\title{
Study on the Development Process and Trends of Comparative Education Research Methods
}

\author{
Sidong Guo \\ Harbin Normal University Harbin, Heilongjiang
}

Keywords: Comparative Education; Research Methods; Process; Trends

\begin{abstract}
The comparative education has created its own unique research method during its development process and this paper attempts to review its three development stages: method reference period, factor analysis period and social scientific methods period so as to predict the research methods of comparative education.
\end{abstract}

\section{The Development History of Comparative Education Research Methods}

Since 1817 the French scholar of comparative education Julian firstly and formally suggested the term comparative education and also systemically put forward its research methods and approaches in Research Projects and Preliminary Views on Comparative Education, it appeared in public. The history when comparative education formed its perfect system can be traced back to two hundred years ago. A glittering array of scholars and professionals have tried unremitting efforts to establish their own theories and approaches, which are still being improved. Generally speaking, the development process of comparative education can be divided into three stages: method reference period, factor analysis period and social scientific methods period.

Method Reference Period. The method reference period started when Julian firstly established comparative education and took advantage of reference method until the end of 1990s. The background is the revolution and national system reform. In addition, both European countries and United States began to realize the importance of education and took the initiative to learn from others in terms of education. For example, they assigned people to go abroad on a tour of investigation to introduce advanced experience, which is of pivotal importance. Based on this, we are able to promote the development of education and enhance the integration of all nations. However, there are also defects. For example, people may ignore the inner relation, copy mechanically in disregard of specific conditions. So, there is a glittering array of unexpected errors and negative effects.

Factor Analysis Period. Factor analysis period is the second period of comparative education from the beginning of $20^{\text {th }}$ century to the end of World War II. During this period, factor analysis method is the main research approach and the pioneer is Sadler from United Kingdom. From his perspective, after-school activities are more important than school activities and he even encouraged to restrict school activities. Therefore, in order to fully understand education in foreign countries, we have to visit families so as to find out the truth behind education. ${ }^{[1]}$ Kandel continued and developed the point of Sadler and firstly elaborated the basic theory and approaches of comparative education. In his opinion, the methodology is formed based on the targets. In order to complete the targets, we have to carefully study on the truth behind education systems, including history, the attitude and interest of the public, political theories and other ethnic nationalism etc. ${ }^{[2]}$ Hans contributed to deepening and perfecting the factor analysis method and it developed to the apex. In the meanwhile, he also promote to make the education become more scientific. In his opinion, comparative education should firstly clear its research historical background, and then carry out a comparison in the premise of collecting the education materials of other countries so as to discuss education solutions, which should be mainly about those factors that will affect the education. Those factors, in his eyes, include natural factors, religious factors and secularly relevant factors. Only when we dig deep into those factors can we fully play the function of education. By the way, factor analysis has enhanced the development of education at that time and was widely spread. 
Social Scientific Methods Period. Social scientific methods period is the third stage in the history of comparative education and is from the end of World War II until now, which aim to explore and emphasize the scientific and empirical characteristics. During this period, the 1950s, 1960s are two decades experiencing quick development. At that time, scientific revolution created a fundamental impact on social and production life and the competition in terms of science and education was very fierce while various countries conducted reform to different degrees. Under this situation, the academic activities of comparative education was very active, which was unprecedentedly developed and enriched. Comparative four steps of Bereday, problem approach of Holmes, Quantitative Analysis Method of Noah \& Eckstein, Education insight study of Edmund King were all put forward at that time. The emergence and application of those colorful research methods were improved both in depth and breadth. After entering into 1970s, the comparative education slowed down. In 1980s, the comparative education carried out a deep reflection and. After 1990s, international education formally introduced comparative education and diverse scientific methods were adopted. However, comparative education was faced with a dilemma of crisis in discipline identity, which needs further development.

\section{The Development Characteristics of Comparative Education Research Methods}

Focus on the Education Process Rather than Research Background .We can see that scholars at that time focus on the education system of one country or multiple countries by studying on the their research methods. They used to pay attention to the research background of the education system, highlight the natural factors, political factors, social factors and ethnic factors. All of them ignored the adaptability and blindly recommended. And then they began to pay attention to advanced education ideas of other countries. At present, the teaching process based on the global view is the main focus of scholars and professionals. For example, some scholars suggested to adopt contents comparison methods to study on the education process.

Combination of Qualitative Research and Quantitative Research Methods .Qualitative examination frequently adopts methods of induction in the premise of paying attention to the backgrounds, which was adopted in the early stage. It mainly paid attention to the mutual relation of all the countries or the development process of one country regarding philosophy, moral principles, history, economy, humanity, language and society. In addition, it also combined contents etc. to form the integrity so as to study on the essence. Quantitative research was frequently used after the science and technology development when countries exchanged ideas more often and when professional organizations of comparative education emerged. As a result, it became more convenient to collect the data of the age, gross enrollment ratio, total investment etc. and at the same time in order to improve the science of research results, qualitative examination is also necessary. However, most of the education factors cannot be quantified because of its complexity. Moreover, the education structures all over the world has a big difference and soaring people began to doubt the result tested only by quantitative research methods. After the introspection and debt in 1980s, comparative education began to integrate qualitative examination as well as quantitative research methods.

Introspection and Reconstruction of Theoretical Methods based on its Original Construction.Since Julian took reference method to study comparative education, the theoretical methods and approaches of comparative eduction was being constructed so far. In the first stage, comparative education studied on its external factors and then changed to the internal factors as well as a comprehensive and systematic factor analysis. What's more, its research range also changed from micro level to macro level. After entering into 1980s, comparative education started to introspect and reconstruct while the research methods adopted scientific approaches to describe and explain the culturalism, critical anthropography, method of difference and world order plan etc. The emergence of those research methods were affected by postmodernism and post-colonialism, which to some extent, embodied the result of critical thinking on education and it will further ignited a bigger reform. 


\section{The Development Trend of Comparative Education Research Methods.}

Comparative education has been through two centuries since its establishment. During these two centuries, it became mature, scientific and diverse when scholars and professionals kept exploring.

Scientific Comparative Education.By organizing the research methods of comparative education, we can clearly see its development history from single description to factor analysis and to various scientific research methods, which is also from subjective research to objective research, from random research to systematic research. Finally, it became scientific, rational and critical. Concerning the scientific persecutive, it developed from qualitative research to quantitative research and to scientific research, which depends on the close connection among countries and the emergence of independent organizations. For example, we can conclude that the research methods are becoming more and more scientific when the methods change from qualitative examination to quantitative examination. In the early stage, we paid attention to the data and collect digital stuff including school age, population, entrance rate and investment and then compare the data to other countries and analyze it to get a conclusion. We can see that quantitative examination is indispensable at that time, which made up for the education research methods and promote a big leap forward. However, the big defect of quantitative examination is that lots of data cannot be quantified so we have to combine the quantitative examination along with qualitative examination.

Diverse Comparative Education. We can see that the research methods of comparative education have been changing all the time so as to be enriched and perfected. In addition, scholars of comparative education and professionals have tried unremitting efforts to introduce advanced methods and innovate. At present comparative education has created hundreds of research methods.

A glittering array of scholars have suggested to reconstruct the concept and theory of comparative education so as to strengthen their observation abilities and create unique methods along with six qualification standards: to begin with, the suppose of challenge failure; second, strengthen the unique characteristics of comparative education publications; third, correctly understand the connotation of globalization; fourth, understand the connotation of education economics; fifth, analyze the value of philosophy while avoiding the economic effects; sixth, focus on the future. ${ }^{[3]}$ What's more, some scholars also try to describe the methodological framework from he persecutive of combination so as to predict the possibility of innovative comparative education. In their opinion, the modern comparative education can be divided into five types: first, study on the literatures of empiricism in detail under certain circumstance; second, study on the international disputes, theoretical framework in a wider range; third, study on clear basic theories rather than the relation between constants and background; fourth, study on the relation between social power and control as well as culture and values fifth, study on the theory of comparative education. At the same time, we are able to create learning theory based on integrating the views of social science so as to construct a relatively perfect research system for comparative education. ${ }^{[4]}$

The above opinions can also help to express the voice of lots of scholars and professionals. However, not all the scholars and professionals think the same way. Some of the suggest that it is better to refer to various methods of social science rather than creating unique methods. For example, in anthropology, there is a method called ethnography, which was introduced later by a Canadian scholar called Masemann. Afterwards, he came up with the idea of school ethnography and critic ethnography, which is a successful crossover from one subject to another subject and also facilitated the development of comparative education. Whats's more, deduction, narration, logic and history are common methods adopted in social science and a Chinese scholar called Fu Sonata introduced these methods to make it bigger. [6] To emphasize field study, combination of quantitative and qualitative can be deemed as proper methods of education anthropography. Professor Xu Hui introduced it and further created a unique methods, which highlight the speciality and cross-cultural comparative analysis. Besides, some scholars creatively adopt some new methods. [7]For example, Sun Jieyuan created comparison methods, which pay more attention to the 
authenticity of thoughts as well as the condition and conclusion of analogical thinking and therefore to make it more effective. [8] Furthermore, narrative inquiry and qualitative research methods have been develop rapidly in recent decades.

21 century is the pivotal stage for comparative education. Even though it starts late in China, we can still establish some unique research methods and contribute to make it more colorful based on systematically referring to the advanced methods of foreign countries as well as the special characteristics of China.

\section{References}

[1] [2] [7] Chen Shijian, Xu Hui. The development and research methods of comparative methods [M] Beijing:Commercial Press, 2006

[3] Keith, Comparative education research: The need for reconceptualization and fresh insights, Compare, Och.1999, Vol.29, Iss.3, pg.233.

[4] Patricia Broadfoot, Stones from other hills may serve to polish the jad of this one: Towards a neo-comparative "learnology" of education, Compare, Oct. 1999, Vol.29, Iss.3 pg.217.

[5] Xiang Xianming. Post-colonial status and comparative education [J]. Journal of Beijing Normal University (Social Science Edition), 1999, (3)

[6] Fu Songtao. Scientific positioning of comparative education as a subject: Morphology of education form [J]. Comparative Education Study, 2005 (3)

[8] Sun Jieyuan. Comparison : Comparative education and the essence of innovative thoughts [J].Journal of Southwest China Normal University(Humanities and Social Sciences Edition), $2005(9)$ 